NASA/CR-2002-211743

ICASE Report No. 2002-23

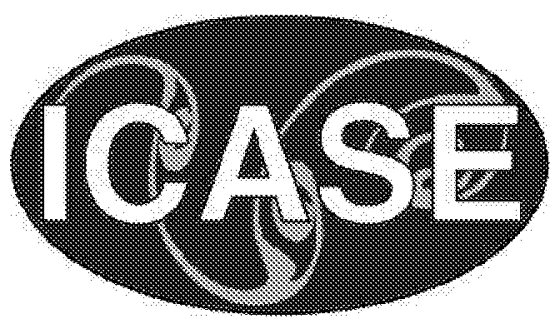

\title{
Analysis of Carbon Nanotube Pull-out from a Polymer Matrix
}

S.J.V. Frankland and V.M. Harik

ICASE, Hampton, Virginia 


\section{The NASA STI Program Office ... in Profile}

Since its founding, NASA has been dedicated to the advancement of aeronautics and space science. The NASA Scientific and Technical Information (STI) Program Office plays a key part in helping NASA maintain this important role.

The NASA STI Program Office is operated by Langley Research Center, the lead center for NASA's scientific and technical information. The NASA STI Program Office provides access to the NASA STI Database, the largest collection of aeronautical and space science STI in the world. The Program Office is also NASA's institutional mechanism for disseminating the results of its research and development activities. These results are published by NASA in the NASA STI Report Series, which includes the following report types:

- TECHNICAL PUBLICATION. Reports of completed research or a major significant phase of research that present the results of NASA programs and include extensive data or theoretical analysis. Includes compilations of significant scientific and technical data and information deemed to be of continuing reference value. NASA's counterpart of peer-reviewed formal professional papers, but having less stringent limitations on manuscript length and extent of graphic presentations.

- TECHNICAL MEMORANDUM. Scientific and technical findings that are preliminary or of specialized interest, e.g., quick release reports, working papers, and bibliographies that contain minimal annotation. Does not contain extensive analysis.

- CONTRACTOR REPORT. Scientific and technical findings by NASA-sponsored contractors and grantees.
- CONFERENCE PUBLICATIONS. Collected papers from scientific and technical conferences, symposia, seminars, or other meetings sponsored or cosponsored by NASA.

- SPECIAL PUBliCATION. Scientific, technical, or historical information from NASA programs, projects, and missions, often concerned with subjects having substantial public interest.

- TECHNICAL TRANSLATION. Englishlanguage translations of foreign scientific and technical material pertinent to NASA's mission.

Specialized services that complement the STI Program Office's diverse offerings include creating custom thesauri, building customized data bases, organizing and publishing research results ... even providing videos.

For more information about the NASA STI Program Office, see the following:

- Access the NASA STI Program Home Page at http://www.sti.nasa.gov

- Email your question via the Internet to help@sti.nasa.gov

- Fax your question to the NASA STI Help Desk at (301) 621-0134

- Telephone the NASA STI Help Desk at (301) 621-0390

- Write to: NASA STI Help Desk NASA Center for AeroSpace Information 7121 Standard Drive Hanover, MD 21076-1320 
NASA/CR-2002-211743

ICASE Report No. 2002-23

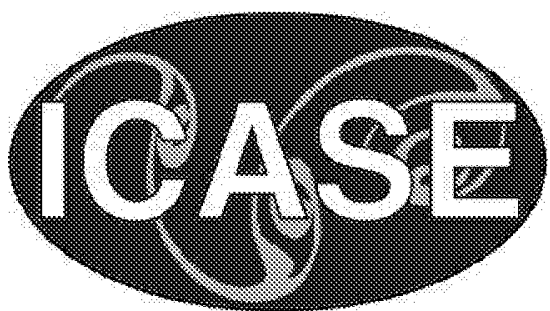

\section{Analysis of Carbon Nanotube Pull-out from a Polymer Matrix}

S.J.V. Frankland and V.M. Harik

ICASE, Hampton, Virginia

ICASE

NASA Langley Research Center

Hampton, Virginia

Operated by Universities Space Research Association 
Available from the following:

NASA Center for AeroSpace Information (CASI)

7121 Standard Drive

Hanover, MD 21076-1320

National Technical Information Service (NTIS)

5285 Port Royal Road

Springfield, VA 22161-2171

(301) 621-0390

(703) $487-4650$ 


\title{
ANALYSIS OF CARBON NANOTUBE PULL-OUT FROM A POLYMER MATRIX ${ }^{*}$
}

\author{
S. J. V. FRANKLAND AND V. M. HARIK
}

\begin{abstract}
Molecular dynamics (MD) simulations of carbon nanotube (NT) pull-out from a polymer matrix are carried out. As the NT pull-out develops in the simulation, variations in the displacement and velocities of the NT are monitored. The existence of a carbon-ring-based period in NT sliding during pull-out is identified. Linear trends in the NT velocity-force relation are observed and used to estimate an effective viscosity coefficient for interfacial sliding at the NT/polymer interface. As a result, the entire process of NT pull-out is characterized by an interfacial friction model that is based on a critical pull-out force, and an analog of Newton's friction law used to describe the NT/polymer interfacial sliding.
\end{abstract}

Key words. carbon nanotube, polymer nanocomposite, interface

\section{Subject classification. Computational Materials Science}

1. Introduction. Polymer nanocomposites with carbon nanotubes (NTs) as fillers have been fabricated and mechanically tested to explore their potential as strong, lightweight materials [1,2]. While some reinforcement of the polymer matrix has been observed in the form of enhanced moduli relative to the polymer matrix alone, a detailed understanding of the NT/polymer interfacial region remains fundamental to the optimization of the mechanical behavior of these composites. The interface plays a significant role in the stress transfer and the consequent improvements in the nanocomposite stiffness and strength. Characterization of the NT/polymer interfacial interactions during pull-out will be the focus of this study.

For traditional fiber-reinforced polymer matrix composites, the interfacial shear strength is typically evaluated by employing fiber pull-out [3] or fiber push-out tests [4]. The fiber decohesion process is characterized by the critical shear stress required to debond the fiber. The value of the shear stress is estimated from the critical axial load using the shear-lag model. For nanocomposites, a similar procedure can be utilized both experimentally [5] and theoretically [6]. For a NT embedded in a polymer matrix, the critical shear stress at the interface has been evaluated via molecular dynamics (MD) simulations and an analog of the shear-lag model [6]. A comparison was made between nanocomposites with and without the nanotube chemically bonded to the polymer indicating that chemical bonds reinforce the interface [6]. This study extends the previous work for the case of a non-bonded NT to refine the analysis of interfacial sliding between the NT and polymer nanostructured surfaces.

In the system simulated here, the matrix is crystalline polyethylene, which interacts with the NT via van der Waals forces represented by the Lennard-Jones potential. MD simulations are used to confirm the critical pull-out force and investigate interfacial sliding as a NT is pulled through the surrounding polymer. NT velocity and displacement are traced in order to characterize the interfacial interactions during NT pull-out. The NT/polymer interfacial friction is described with a relation between the applied force to the NT and the NT velocity that is an analog of the Newton's viscous friction law, which involves an effective viscosity coefficient of the interfacial sliding. Furthermore, an interfacial friction model for the entire pull-out process is proposed.

\footnotetext{
* ICASE, M/S 132C, NASA Langley Research Center, Hampton, VA 23681. This research was supported by the National Aeronautics and Space Administration under NASA Contract No. NAS1-97046 while the authors were in residence at ICASE, NASA Langley Research Center, Hampton, VA 23681-2199.
} 
2. Molecular Structure of a Nanotube/Polymer System. The nano-scale material system in this study is composed of a carbon NT and a polyethylene (PE) matrix. Specifically, a $(10,10)$ carbon NT is embedded in crystalline polymer matrix (Figures 1 (a) and (b)). The system contains about 23,000 atoms including an 880-C-atom NT and 178 chains of 42 methylene units with the hydrogen atoms explicitly included. The dimensions of the system are $\sim 6 \times 6 \times 6 \mathrm{~nm}$. In the molecular dynamics (MD) simulations, the entire system is represented with the hydrocarbon potential developed by Brenner, et al. [7]. The system is replicated across periodic boundaries in each of the 3-dimensions, thereby making the NT and the PE chains infinitely long. This composite is similar to the crystalline non-bonded polyethylene one used in the previous work [6], and the detailed chemical description is kept for consistency.

(a)

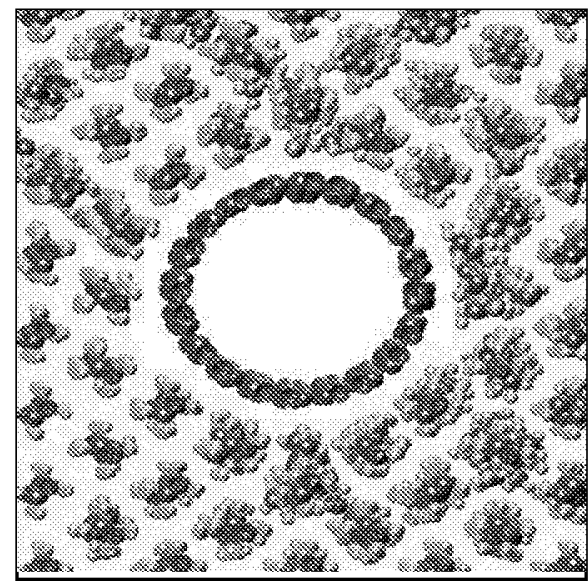

(b)

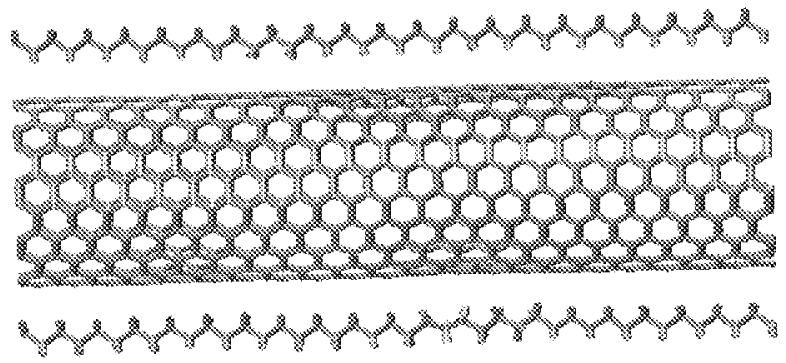

FIGURE 1. Molecular structure of crystalline polyethylene/NT composite: (a) a cross-section of central $3.6 \mathrm{~nm}$ of the sample (b) a side view of NT and two nearby polyethylene chains.

The entire NT pull-out process is simulated by MD. As the sample cell is periodic, the pull-out is simulated by pulling the NT through, rather than out of, the PE matrix. A unidirectional force is applied to each atom of the NT along the NT axis. The pull-out force is increased incrementally over time (Figure 1). The simulation is run for $\sim 100,000 \mathrm{MD}$ time steps of $0.5 \mathrm{fs}$. Data generated from MD simulation of this system forms the input to the interfacial friction model described below.

3. Characterization of Nanotube Pull-out and Numerical Results. The MD simulation captures the full NT pull-out process. Initially, after a sufficient amount of force is applied to the NT in the simulation, interfacial sliding begins. In Figure 2, the increments of applied force are shown, and over time, the velocity (Figure 3) and the displacement of the NT are monitored (Figure 4). Following the observed variations in the axial velocity of the NT (Figure 3), the entire pull-out process can be divided into several stages. In the simulation, the axial velocity of the NT is sufficiently greater than the velocity of the surrounding polymer in the vicinity of the NT, and the latter is therefore neglected in the analysis. A detailed analysis of the NT velocity data is subsequently carried out to characterize the pull-out process, in general, and interfacial sliding, in particular. 


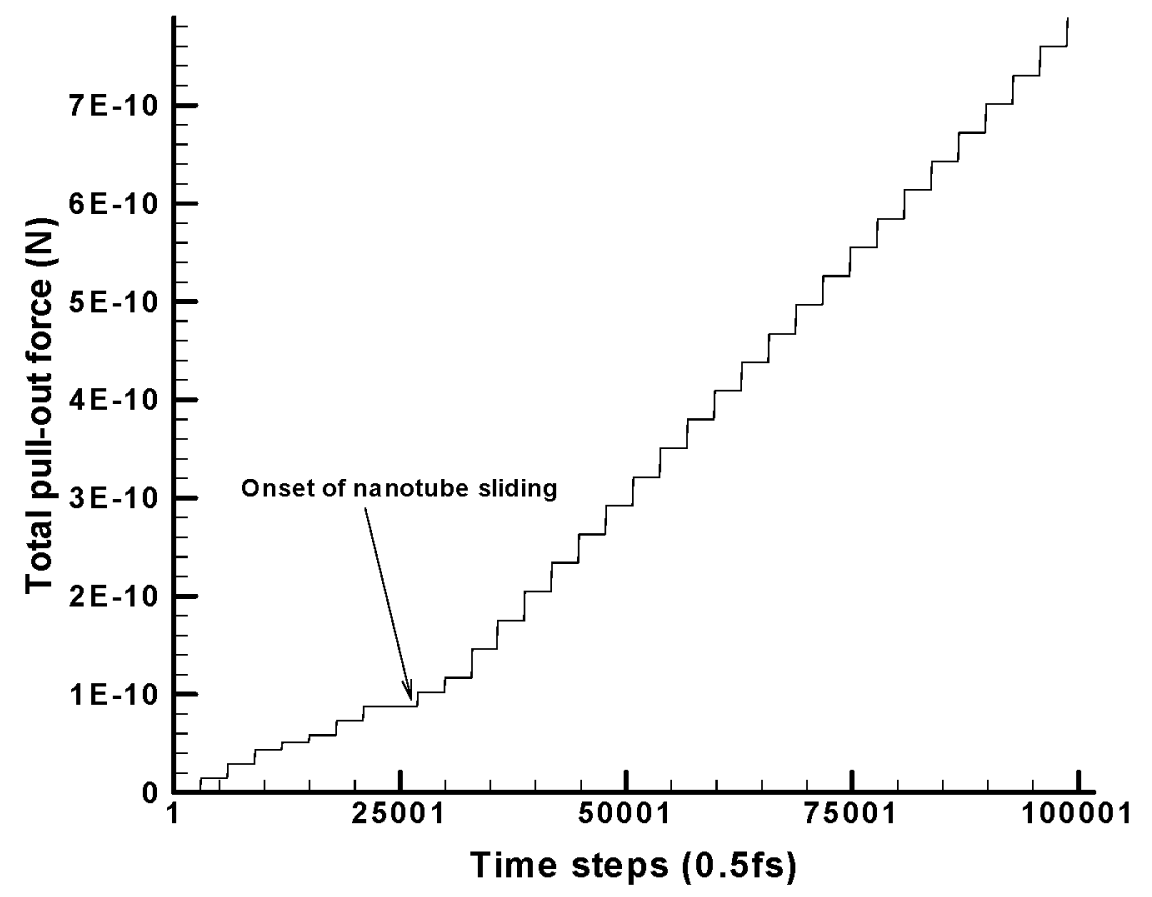

FIGURE 2. The increments of axial force applied to the nanotube over time.

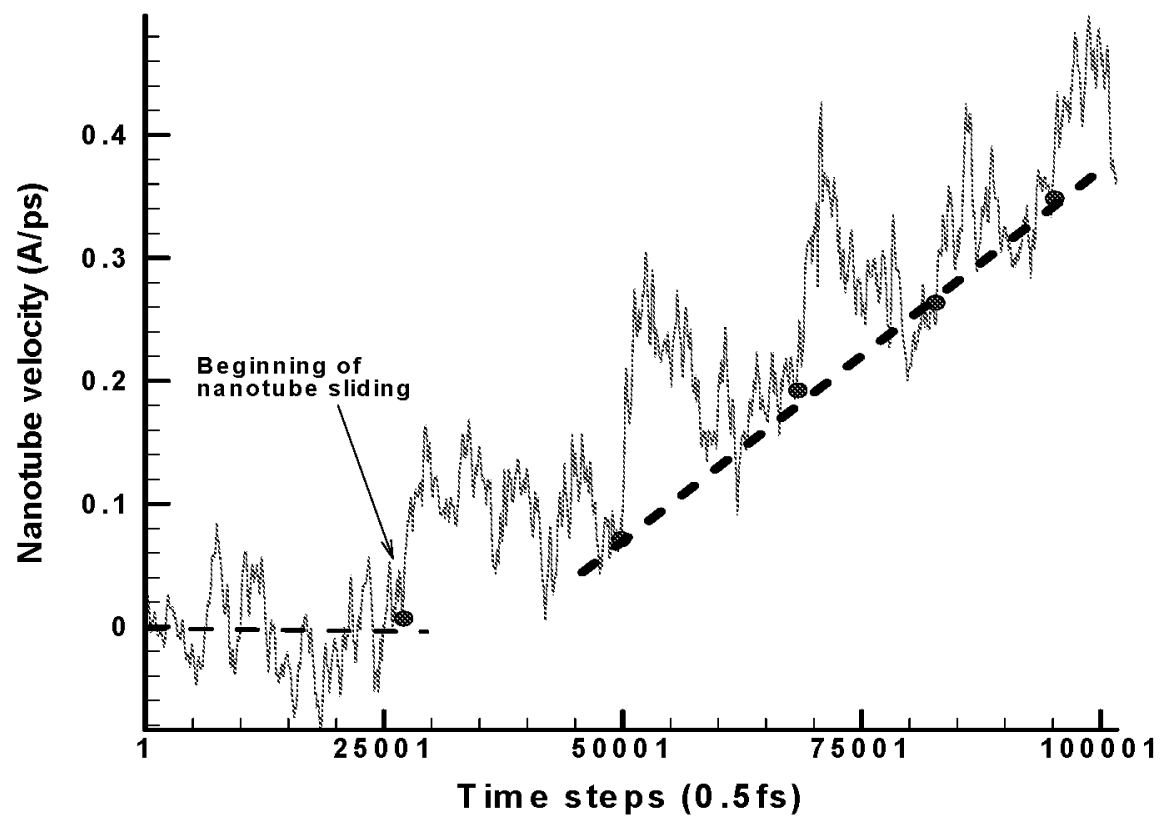

FIGURE 3. Velocity of the center of mass of a carbon NT during the simulated pull-out. 


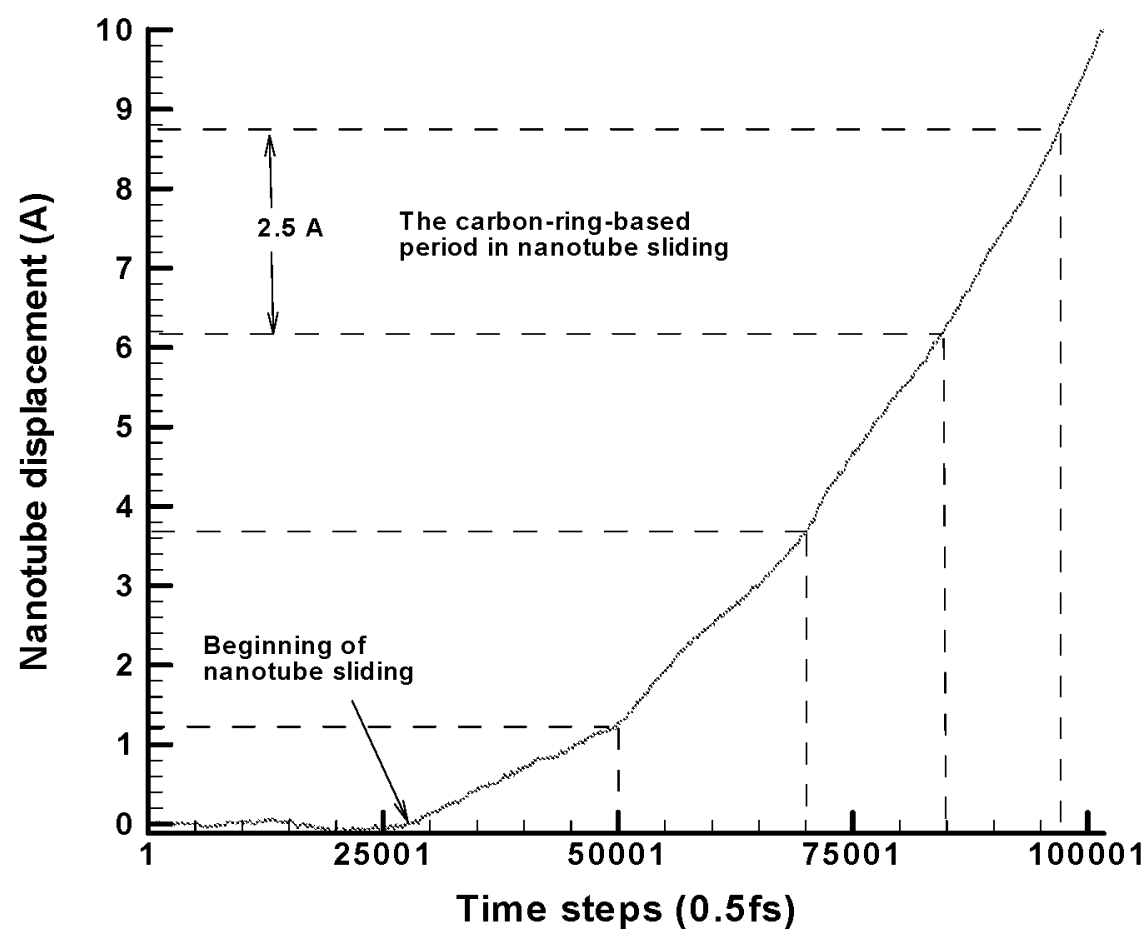

FIGURE 4. Displacement of individual carbon atoms of the NT during the pull-out process.

Prior to the onset of sliding, the NT experiences thermal vibrations and interacts with the adjacent polymer chains in equilibrium at $300 \mathrm{~K}$. The effect of these interactions on NT axial velocity is illustrated in Figure 3 for the first 27,000 time steps (up to time of pull-out, $t_{\text {pull-out }}$ ) as the applied force is being gradually increased to $0.1 \mathrm{nN}$. Beyond this critical force, the NT starts to slide through the polymer matrix. Following the details of MD simulation data presented in Figures 3 and 4 as well as the established conceptual framework for viscoplastic interfacial yielding [8], the entire NT pull-out process can be described by four stages.

1) Initially, an equilibrium exists between the NT and the surrounding polymer chains $\left(t<t_{\text {pull-out }} \approx\right.$ 27,000 time steps). In this equilibrium configuration, there exists a net strength of interaction between the polymer and the NT which must be overcome for pull-out to occur.

2) At an applied force of about $0.1 \mathrm{nN}$, accession of the energy/force barrier occurs initiating slippage between the NT and the polymer. This onset of slippage is marked by a noticeable increase in the axial velocity of the NT, which is observed at $t=t_{\text {pull-out }} \approx 27,000$ time steps.

3) Slippage of the NT in the polymer cavity fully develops during a transition stage between $t_{\text {pull-out }}$ and $t_{s s} \approx 50,000$ time steps, where $t_{s s}$ refers to the onset of steady sliding.

4) The steady sliding of the NT (for $t>t_{s s}$ ) is characterized by semi-periodic variations in NT sliding velocity as the NT accelerates under step-wise increases in the applied force. The onset of periodic accelerations in the NT sliding is marked by dots in Figure 3.

Similar stages of interfacial sliding have been observed for other surfaces [9]. 
The observed periodic variations in the NT axial velocity (Figure 3) can be related to the size of the carbon rings in the NT periodic structure. From a comparison of the velocity and displacement data in Figures 3 and 4, a correlation is evident between the distance traveled by the NT and the period of the velocity oscillations. The movement of the NT can, therefore, be scaled by the width of a carbon ring, $a$. In Figure 3, the dots on the velocity trace mark the onset of accelerations, which are related to the ascent of local energy barriers at the beginning of the carbon ring period. These onsets occur sooner as the NT kinetic energy increases relative to the local energy barriers to NT sliding. In the displacement trace plotted in Figure 4, there are noticeable changes in the slope marked by the dotted lines, which occur simultaneously with the beginning of the accelerations in the velocity trace. These changes in slope are separated by $2.46 \mathrm{~A}$, the width of carbon rings, $a$.

4. Interface Model and Nano-scale Friction Laws. For fiber-reinforced polymer matrix composites undergoing large deformation, interfacial debonding and sliding can be simulated by elastoplastic, viscous or viscoplastic models for matrix materials accompanied by a phenomenological interface potential for the fiber-matrix interaction [8]. A Bingham-type model [8] for viscoplastic failure of the interface relates the shear stress, $\tau$, to the strain rate, $\dot{\gamma}$, via the Newton's friction law $(\tau=\mu \dot{\gamma})$ after the yield stress, $\tau_{0}$, is reached:

$$
\tau=\tau_{0}+\mu_{m} \dot{\gamma}
$$

Here, $\mu$ and $\mu_{m}$ are viscosities of a fluid and a viscous matrix material, respectively. Newton's friction law [10] is defined for the adjacent layers of a continuum fluid that is subjected to shearing. At the nanometer level, an analog of this friction law can be applied, which uses the forces applied to the NT and the velocity information (Figure 5) to determine an effective viscosity. Furthermore, the stresses and strain rates can be recast in terms of average forces and velocity gradients derived from the MD simulations of NT sliding.

In order to characterize and then model the sliding between a NT and the surrounding polymer chains on a length-scale level larger than the carbon rings, multiple carbon ring lengths of simulation data are needed for sufficiently meaningful averaging of the contributions from local NT structure. The relative sliding involves two surfaces, that is, the NT and polymer sliding surfaces. For the longitudinal direction, the NT length, $L_{N T}$, should be sufficiently long, that is, $L_{N T} / a>10$, where $a$ is the width of a carbon ring. The number 10 implies an order of magnitude difference. Likewise, for the perimeter of the NT/polymer interface, the NT radius should satisfy a similar inequality: $2 \pi\left(R_{N T}+\bar{h}_{V d W} / 2\right) / a>10$, where $R_{N T}$ is the NT radius and $\bar{h}_{V d W}$ is an average surface separation caused by the van der Waals forces. The considered NT/polymer system satisfies all these averaging (or homogenization [11]) criteria.

At the length-scale level larger than the carbon rings, an analog of Newton's friction law (4.1) can be developed as follows. The average shear stress, $\left\langle\tau_{r z}>\right.$, for planar sliding interactions can be defined as $<\tau_{r z}>\approx<>_{\text {pull }}\left(A_{s s}\right)$, where $\left.<\right\rangle_{\text {pull }}$ is the average force applied to the NT and $A_{s s}$ is the common interfacial area of steady sliding. The strain rate, $\dot{\gamma}$, can be estimated by $\dot{\gamma} \approx \partial\left\langle V_{z}\right\rangle / \partial r$, where $\left\langle V_{z}\right\rangle$ is the average NT velocity in the z-direction and $r$ is the radial distance. Then, the nano-scale analog of Newton's law for steady NT/polymer interfacial sliding is

$$
<\tau_{r z}>=\mu_{e f f} \frac{\partial<V_{z}>}{\partial r}
$$


where $\mu_{\text {eff }}$ is an effective viscosity for the NT/polymer interfacial sliding. As a result, an interfacial friction model for the entire NT pull-out process can be developed for the total shear stress, $\left\langle\tau_{r z}\right\rangle$ pull, which, in addition to the sliding component $\left\langle\tau_{r z}\right\rangle$, includes an initial threshold pull-out stress, $\tau_{0}$ :

$$
<\tau_{r z}>_{p u l l}=\tau_{0}+\mu_{\text {eff }} \frac{\partial<V_{z}>}{\partial r} .
$$

After approximating the change in velocity across the NT/polymer interfacial separation, $\bar{h}_{V d W}$, as the average NT velocity, $\left\langle V_{z}\right\rangle$,

$$
<\tau_{r z}>_{p u l l}=\tau_{0}+\mu_{e f f} \frac{<V_{z}>}{\bar{h}_{V d W}},
$$

where the strain rate is $\partial\left\langle V_{z}>/ \partial r \approx\left\langle V_{z}>/ \bar{h}_{V d W}\right.\right.$. The values of the average NT velocity, $\left\langle V_{z}\right\rangle$, and the van der Waals separation, $\bar{h}_{V d W}$, are determined from the MD simulation.

To complete the description of the interface model for the NT pull-out process, the effective viscosity, $\mu_{\text {eff, }}$ can be determined from the MD simulation. Such a viscosity coefficient depends on the nature of NT/polymer interfacial interactions. In the non-bonded system simulated, the velocity of the NT is, on average, linearly related to the average applied force, $<\beta$, as can be observed for times longer than $t_{s s}$ in Figure 5. The slope of this relation, $\chi_{\text {eff, }}$ can be parameterized by the MD simulation data. The resulting force-velocity dependence

$$
<f>=\chi_{\text {eff }}<V_{z}>
$$

is an analog of the friction law in equation (4.2). The applied force, $\langle\beta\rangle$, in equation (4.4) is related to the sliding component of the shear stress as in equation (4.2) by the force balance:

$$
<f>=<\tau_{r z}>A_{s s} .
$$

Therefore, the "effective viscosity coefficient" $\chi_{\text {eff }}$ can be related to the effective viscosity $\mu_{\text {eff }}$ via

$$
\mu_{e f f}=\frac{\chi_{e f f} \bar{h}_{v d W} / L_{N T}}{2 \pi\left(R_{N T}+\bar{h}_{v d W} / 2\right)} .
$$

Following the analogy, the interfacial friction model for the entire pull-out process is

$$
<f>_{\text {pull }}=f_{0}+\chi_{\text {eff }}<V_{z}>\text {, }
$$

where $f_{0}$ is the critical pull-out force, which is also available directly from the MD simulation.

5. Characterization of the Interfacial Sliding. The interfacial friction model (4.7) involves the critical pull-out force, $f_{0}$, and the "effective viscosity coefficient", $\chi_{e f f}$, the values of which can be obtained from the MD simulation of the pull-out process. For every incremental force loading, the NT velocity variations shown in Figure 3 are plotted in Figure 5 as a range represented by a vertical line. These ranges correspond to NT sliding velocity once the critical pull-out force, $f_{0}$, at $0.1 \mathrm{nN}$ is reached. After this point, the force-velocity dependence can be approximated by a linear relation (the solid line) [9]. The inverse of the slope of the resulting line is the coefficient $\chi_{\text {eff, }}$ which is $1.5 \pm 0.3(\mathrm{nN} \mathrm{ps}) / \mathrm{A}$. This slope can be estimated from dashed lines like those shown in Figure 5, which bound the NT velocity variations during 
NT sliding. Once the value of the coefficient $\chi_{\text {eff }}$, is determined, the effective viscosity, $\mu_{\text {eff }}$, can be calculated from equation (4.6) as $0.2 \mathrm{cP}$ (centi-Poise) assuming an average van der Waals separation, $\bar{h}_{V d W}$, of $3.4 \mathrm{~A}$, the NT length, $L_{N T}$, of $53.65 \mathrm{~A}$ and the NT radius, $R_{N T}$, of $6.8 \mathrm{~A}$. This result is close to the viscosity of pentane at $0.22 \mathrm{cP}$ at room temperature [12]. These values complete the parameterization of the interfacial model (4.7), which approximates the force-velocity dependence during the entire NT pullout process (Figure 5).

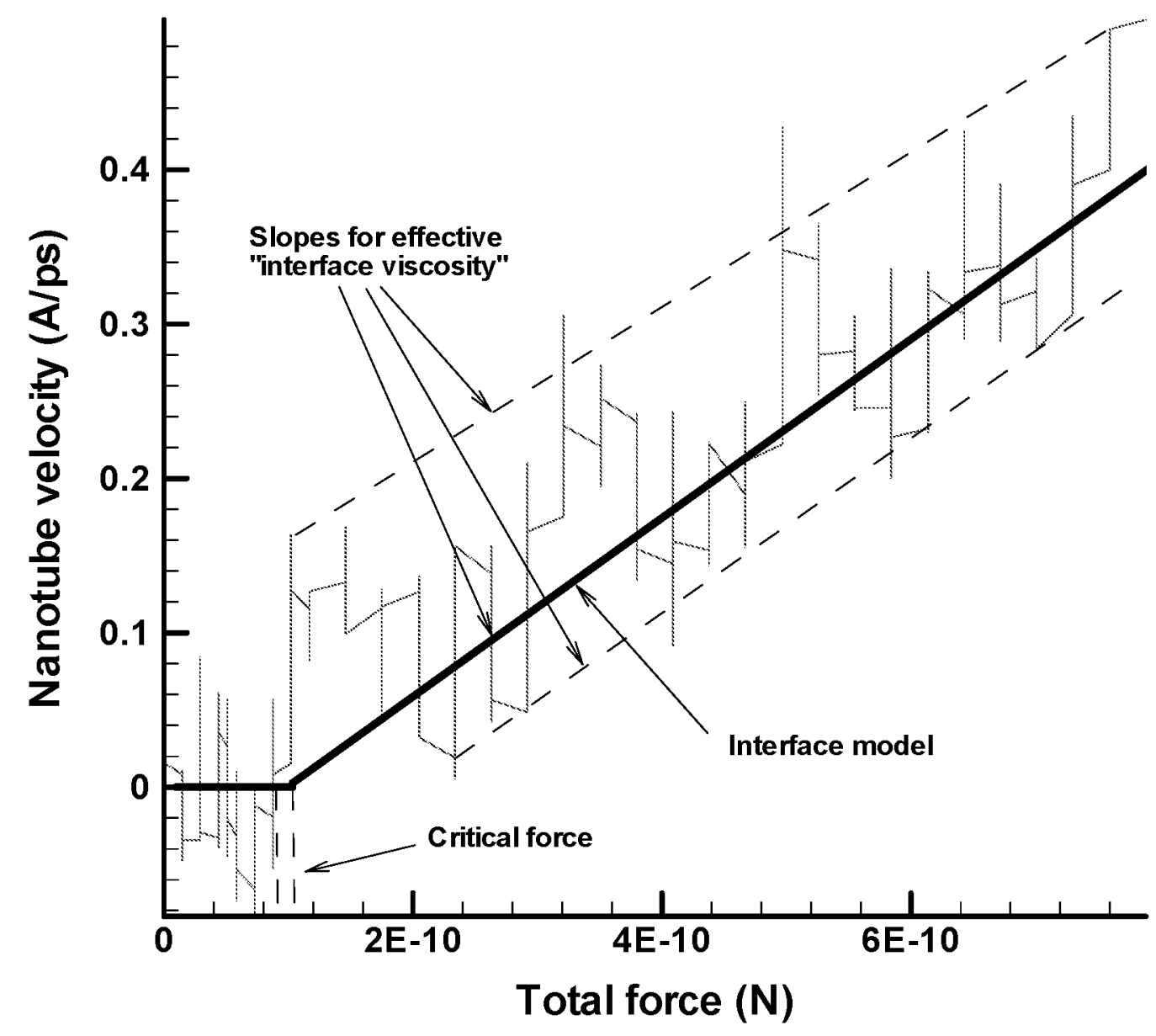

FIGURE 5. Comparison between the viscoplastic interface model and MD simulation data.

6. Concluding Remarks. Carbon nanotube (NT) pull-out from a crystalline polymer matrix is simulated with molecular dynamics (MD) and an interfacial friction model. The resulting interfacial sliding between the adjacent surfaces of the NT and the surrounding polymer has been investigated with MD simulations and modeled by a nano-scale analog of Newton's friction law. Verification has been given that the length scales involved in the simulation ensure a meaningful representation of sliding properties. The friction model developed involves the pull-out force, an effective viscosity, and the strain rate, which are parameterized directly from the MD data. 
The entire pull-out process has been divided into four stages: 1) an initial equilibrium state, 2) the onset of NT slippage at the threshold pull-out force, 3) transition between the initial and steady sliding, and 4) steady sliding. When steady sliding is reached, a carbon-ring-based period in NT sliding velocity is observed, as the NT passes through the polymer matrix. On average, interfacial interactions during NT sliding can be approximated by a linear force-velocity relationship whose slope is the effective viscosity coefficient in the friction model. The magnitude of the viscosity is dependent on the chemical interactions at the NT/polymer interface, and is therefore, a potentially important structure/property relation for the design and optimization of novel NT-reinforced polymer composites. In this study, the weak interactions observed are inherent to the non-bonding van der Waals forces used to describe the NT/polymer interface.

The interfacial friction model developed here is relevant to the evaluation of interfacial stress transfer in nanocomposites.

\section{REFERENCES}

[1] L. S. SCHADLER, S. C. GIANNARIS and P. M. AJAYAN, Load transfer in carbon nanotube epoxy composites. Appl. Phys. Lett., 73 (1998), p. 3842; P. M. AJAYAn, L. S. Schadler, S. C. GIANNARIS, and A. RUBIO, Single-walled carbon nanotube-polymer composites: Strength and weakness. Adv. Mater., 12 (2000), p. 750.

[2] M. S. P. SHAFFER and A. H. WINDLE, Fabrication and characterization of carbon nanotube/poly(vinyl alcohol) Composites. Adv. Mater., 11 (1999), p. 937.

[3] M. R. PigGotT, A new model for interface failure in fibre-reinforced polymers. Composites Sci. Techn., 55 (1995), p. 269.

[4] V. T. BECHEL and N. R. SOTTOS, A comparison of calculated and measured debond length from fiber push-out tests. Composites Sci. Techn., 58 (1998), p. 1727.

[5] M.-F. YU, B. S. FILES, S. AREPALLI and R. S. RUOFF, Tensile loading of ropes of single wall carbon nanotubes and their mechanical properties. Phys. Rev. Lett., 84 (2000), p. 5552.

[6] S. J. V. FRANKLAND, A. CAGLAR, D.W. BRENNER and M. GRIEBEL, Molecular simulation of the influence of chemical cross-links on the shear strength of carbon nanotube-polymer interfaces. J. Phys. Chem. B, 106 (2002), p. 3046.

[7] D. W. BRENNER, Empirical Potential for Hydrocarbons for Use in Simulating the Chemical Vapor Deposition of Diamond Films. Phys. Rev. B, 42 (1990), p. 9458. A slightly modified form is used. (D. W. Brenner, O. A. Shenderova, S. B. Sinnott and J. A. Harrison, unpublished.)

[8] V. M. HARIK and R. A. CAIRNCROSS, Formation of interfacial voids around inclusions in weakly-bonded viscoplastic matrices. Mech. Mater., 32 (2000), p. 807.

[9] B. N. J. PERSSON, Sliding friction, Surf. Sci. Reports, 33 (1999), p. 83.

[10] G. K. BATChELOR, Introduction to Fluid Mechanics. Cambridge University Press, Cambridge, 1980.

[11] V. M. HARIK, Applicability of the continuum-beam models in the mechanics of carbon nanotubes and nanorods. Solid State Communications, 120 (2001), p. 331.

[12] CRC Handbook of chemistry and physics (ed. D. R. Lide), $75^{\text {th }}$ edition. CRC Press Inc., Boca Raton, 1994, p. 6-243. 


\begin{tabular}{|c|c|c|c|}
\hline \multicolumn{3}{|c|}{ REPORT DOCUMENTATION PAGE } & $\begin{array}{l}\text { Form Approved } \\
\text { OMB No. 0704-0188 }\end{array}$ \\
\hline \multicolumn{4}{|c|}{ 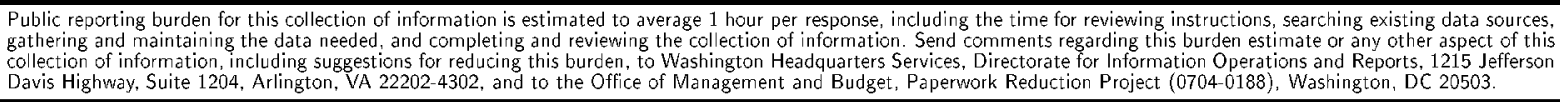 } \\
\hline 1. AGENCY USE ONLY(Leave blank) & $\begin{array}{l}\text { 2. REPORT DATE } \\
\text { July } 2002\end{array}$ & \multicolumn{2}{|c|}{$\begin{array}{l}\text { 3. REPORT TYPE AND DATES COVERED } \\
\text { Contractor Report }\end{array}$} \\
\hline \multicolumn{3}{|c|}{$\begin{array}{l}\text { 4. TITLE AND SUBTITLE } \\
\text { ANALYSIS OF CARBON NANOTUBE PULL-OUT FROM A } \\
\text { POLYMER MATRIX }\end{array}$} & \multirow[t]{2}{*}{$\begin{array}{l}\text { 5. FUNDING NUMBERS } \\
\text { C NAS1-97046 } \\
\text { WU } 505-90-52-01\end{array}$} \\
\hline \multicolumn{3}{|c|}{$\begin{array}{l}\text { 6. AUTHOR(S) } \\
\text { S.J.V. Frankland and V.M. Harik }\end{array}$} & \\
\hline \multicolumn{2}{|c|}{$\begin{array}{l}\text { 7. PERFORMING ORGANIZATION NAME(S) AND ADDRESS(ES) } \\
\text { ICASE } \\
\text { Mail Stop } 132 \mathrm{C} \\
\text { NASA Langley Research Center } \\
\text { Hampton, VA } 23681-2199\end{array}$} & & $\begin{array}{l}\text { 8. PERFORMING ORGANIZATION } \\
\text { REPORT NUMBER } \\
\text { ICASE Report No. } 2002-23\end{array}$ \\
\hline \multicolumn{3}{|c|}{$\begin{array}{l}\text { 9. SPONSORING/MONITORING AGENCY NAME(S) AND ADDRESS(ES) } \\
\text { National Aeronautics and Space Administration } \\
\text { Langley Research Center } \\
\text { Hampton, VA 23681-2199 }\end{array}$} & $\begin{array}{l}\text { 10. SPONSORING/MONITORING } \\
\text { AGENCY REPORT NUMBER } \\
\text { NASA/CR-2002-211743 } \\
\text { ICASE Report No. } 2002-23\end{array}$ \\
\hline \multicolumn{4}{|c|}{$\begin{array}{l}\text { 11. SUPPLEMENTARY NOTES } \\
\text { Langley Technical Monitor: Dennis M. Bushnell } \\
\text { Final Report } \\
\text { To appear in the Materials Research Society Symposium Proceedings. }\end{array}$} \\
\hline \multicolumn{2}{|c|}{$\begin{array}{l}\text { 12a. DISTRIBUTION/AVAILABILITY STATEMENT } \\
\text { Unclassified-Unlimited } \\
\text { Subject Category } 34 \\
\text { Distribution: Nonstandard } \\
\text { Availability: NASA-CASI (301) 621-0390 }\end{array}$} & 12b. DISTR & 12b. DISTRIBUTION CODE \\
\hline \multicolumn{4}{|c|}{$\begin{array}{l}\text { 13. ABSTRACT (Maximum } 200 \text { words) } \\
\text { Molecular dynamics (MD) simulations of carbon nanotube (NT) pull-out from a polymer matrix are carried out. As } \\
\text { the NT pull-out develops in the simulation, variations in the displacement and velocities of the NT are monitored. } \\
\text { The existence of a carbon-ring-based period in NT sliding during pull-out is identified. Linear trends in the NT } \\
\text { velocity-force relation are observed and used to estimate an effective viscosity coefficient for interfacial sliding at the } \\
\text { NT/polymer interface. As a result, the entire process of NT pull-out is characterized by an interfacial friction model } \\
\text { that is based on a critical pull-out force, and an analog of Newton's friction law used to describe the NT/polymer } \\
\text { interfacial sliding. }\end{array}$} \\
\hline \multirow{2}{*}{\multicolumn{2}{|c|}{$\begin{array}{l}\text { 14. SUBJECT TERMS } \\
\text { carbon nanotube, polymer nanocomposite, interface }\end{array}$}} & & $\begin{array}{c}\text { 15. NUMBER OF PAGES } \\
13\end{array}$ \\
\hline & & & \begin{tabular}{|c|} 
16. PRICE CODE \\
$\mathrm{A} 03$
\end{tabular} \\
\hline $\begin{array}{l}\text { 17. SECURITY CLASSIFICATION } \\
\text { OF REPORT } \\
\text { Unclassified }\end{array}$ & $\begin{array}{l}\text { 18. SECURITY CLASSIFICATION } \\
\text { OF THIS PAGE } \\
\text { Unclassified }\end{array}$ & $\begin{array}{l}\text { 19. SECURITY CLASSIFICATION } \\
\text { OF ABSTRACT }\end{array}$ & $\begin{array}{l}\text { 20. LIMITATION } \\
\text { OF ABSTRACT }\end{array}$ \\
\hline
\end{tabular}

